\title{
Testing race models by estimating the smaller of two true mean or true median reaction times: An analysis of estimation bias
}

\author{
JEFF MILLER and ALBANO LOPES \\ University of California-San Diego, La Jolla, California
}

\begin{abstract}
Researchers testing certain race models of reaction time sometimes want to estimate the smaller of the true mean (or median) reaction times in two experimental conditions. Standard practice is to collect a number of observations in each condition, and then take the smaller of the observed mean reaction times as the estimate of the smaller of the two true means. Unfortunately, this is a biased procedure, tending in the long run to underestimate the smaller of the two true means. This article presents computer simulations that investigate the size of this bias as a function of sample size, variance and shape of RT distributions, and separation between the true means of the two conditions. The amount of bias is directly related to the standard errors of the mean reaction times and inversely related to the separation between the true means. Bias can exceed $50 \mathrm{msec}$ under some conditions that might be found in an actual experimental setting. Several other estimators were also examined in the simulations, and some had much smaller, though still nonnegligible, bias. By using estimators that are biased in opposite directions, it is possible to construct a conservative interval estimate of the true value being sought. Implications for testing race models are discussed.
\end{abstract}

This article is concerned with a statistical problem that arises in testing certain kinds of race models of reaction time (RT). One test of these models requires an estimate of the smaller of the true mean or median RTs in two experimental conditions, because the smaller of the two true values is needed as a control condition. The standard procedure is to estimate this value by taking the average, across subjects, of the smaller of the individual subject averages in the two conditions. The statistical problem is that this estimation procedure is biased, tending in the long run to underestimate the true value being estimated. The underestimation bias generally favors the race models and works against the most plausible alternatives to race models.

In this article we first distinguish two kinds of race models and indicate which one is subject to the statistical problem we have studied. Then we explain the source of the estimation bias and report computer simulations designed to measure its size. Finally, we consider other estimation procedures that might do better than the standard one, and report simulations designed to evaluate these alternative procedures. Our conclusion is that one of these alternative procedures is much better than the standard one, and that this new estimator should be used in all cases

This research was supported by Grant PHS-MH40733 from the National Institute of Mental Health to the first author. We would like to thank Patricia Haden, Lester Krueger, David Phillips, and an anonymous reviewer for helpful comments on the exposition. Requests for reprints should be addressed to the first author at the Department of Psychology, C-009, University of California-San Diego, La Jolla, California 92093. in which a test of race models (or any other test, for that matter) requires estimating the smaller of two true means or medians.

\section{Race Models}

In race models, a response is generated by the faster of two separate processes (e.g., Logan, 1985). For example, suppose a subject must classify stimuli into the tall blue ones and the short red ones. A race model would have separate processes for classification by shape and color, and the classification of any individual stimulus would result from the faster of the two separate classification processes.

An examination of the literature reveals two kinds of race models (e.g., Garner, 1969). In one, the two postulated processes race each time a stimulus is presented, so we call this the trial-by-trial race model. In the shape and color example, both the shape classification process and the color classification process would begin each time a stimulus was presented, and the response would be determined by whichever process finished first.

In the other type of race model, subjects use one particular process on all the trials in the condition in which either is sufficient to determine the response. They choose whichever process is faster in the long run (i.e., the one that has a shorter average finishing time), so that they can respond as quickly as possible. It may be the case that one process has a faster average for some subjects and the other process has a faster average for other subjects, so we call this the subject-by-subject race model.

The trial-by-trial and subject-by-subject race models are quite different. Other things being equal, subjects could 
respond faster under the trial-by-trial race model than under the subject-by-subject race model, because they could take advantage of the overlapping distributions of random finishing times for the two processes (Raab, 1962). Furthermore, the trial-by-trial race model is potentially applicable in a wider range of experimental conditions, because it could be used even when the subject does not know in advance which process will be informative. For example, the subject might be asked to classify stimuli as tall and/or blue versus short and/or red, in which case it would not be clear whether color or shape would be sufficient to respond on any trial. The subject-by-subject race model could not be applicable in such cases, because the subject would not know which process to rely on before a trial started. Finally, there is a sense in which the trial-by-trial race model is easier to implement, because the faster process on each trial should be relatively easy to determine. To implement the subject-by-subject race model, on the other hand, each subject must be able to choose the process with the smaller average finishing time. If distributions of finishing times overlap to a great extent, it might be difficult to construct a mechanism which would allow each subject to select the faster process. ${ }^{1}$

All of these factors tend to make the trial-by-trial model more interesting than the subject-by-subject model, and it has certainly received more attention in recent studies. This model can be tested by examining cumulative distribution functions of RT, and statistical problems involved in testing this model have been discussed extensively (Ashby \& Townsend, 1986; Colonius, 1986; Eriksen, 1988; Miller, 1978, 1981, 1982; Ulrich \& Giray, 1986).

Even if the trial-by-trial race model seems more interesting or intuitively appealing, the subject-by-subject race model must be retained as an alternative until it can be ruled out experimentally. In fact, the subject-by-subject model has some appealing features of its own. Garner (1969), who referred to it as the "selective serial processing" model, noted that it could be used in a simple serial processing system, whereas the trial-by-trial race model requires subjects to process dimensions in parallel. Even if parallel processing is possible, the subject-by-subject race model could lead to faster responses if there were attentional or capacity limitations. With limited attention, subjects may be able to go much faster by committing themselves in advance to one process and allocating all their attention to it. In support of this idea, for example, Hawkins (1969) found that subjects were faster to detect a difference on a single stimulus dimension (e.g., color or shape) when it was the only relevant dimension than when other dimensions were also relevant. If the advantage of concentrating attention is larger than the advantages associated with the trial-by-trial race model, then the subject-by-subject model could lead to faster responses than would be possible under the trial-by-trial model.

The subject-by-subject race model has figured most prominantly in the study of interactions among perceptual dimensions in classification tasks. In one of the first studies of this type, Biederman and Checkosky (1970) investigated the use of redundant stimulus information in simple discrimination tasks. Subjects were required to make two-choice discriminations in three conditions: stimuli varying in color, stimuli varying in form, and stimuli varying redundantly in color and form. The main question was whether subjects used information from both attributes to make their judgments in the redundant condition, or whether each subject used only the one attribute that could be judged faster, as would be assumed by a subject-by-subject race model. The race model could be rejected if the true mean RT in the redundant condition were less than the smaller of the two true means in the single-dimension control conditions, and it could then be concluded that subjects use information from both attributes in the redundant condition. ${ }^{2}$ Thus, a subject-bysubject race model can be tested by comparing the true mean RT in the redundant condition against the smaller of the two true mean RTs in the single-dimension control conditions. Obviously, this requires a statistical estimate of the smaller of the two true means. ${ }^{3}$ As discussed in the next section, the standard procedure for estimating this value is biased.

The subject-by-subject race model has become such a standard model in studies of perceptual interactions that it is not always stated explicitly. However, it is clear that this model is being considered from the fact that many studies test for perceptual interactions with variants of the technique used by Biederman and Checkosky (1970) (e.g., Callaghan, Lasaga, \& Garner, 1986; Hughes, 1986).

In addition to being considered in studies of perceptual interactions, the subject-by-subject race model has been considered explicitly in studies addressing the issue of serial and parallel processing in visual search (e.g., Van der Heijden, La Heij, \& Boer, 1983). In particular, the question was whether responses to redundant targets presented on different channels at the same time are faster than responses to the faster of the two single targets. In some analyses, these investigators considered the possibility of different average processing times for targets on different channels.

\section{Estimation Problem}

To estimate the smaller of the true mean RTs corresponding to two single-process control conditions, the standard procedure- which seems quite natural-is to collect some observations in each control condition, and then use the smaller of the two observed means as an estimate of the smaller of two true means. ${ }^{4}$ This procedure is, unfortunately, statistically biased: The smaller of the two observed means tends to underestimate the smaller of the two true means, on the average across subjects. As a result, the estimated mean for the faster of the control conditions will be too small, and the race model will tend not to be rejected even if, in violation of the model, the true mean for the critical two-dimension condition is actually faster than the faster of the two single-dimension control conditions. Indeed, this sort of violation of the 
model is exactly what is expected under many alternative models (Miller, 1982).

The reason for the bias in the standard procedure is not difficult to understand. Suppose the true means for two conditions are nearly the same: say, 500 and $501 \mathrm{msec}$. We want to estimate the smaller of the two true means, which is clearly 500 . An unbiased procedure for estimating the true value (500) is to select the sample mean for the 500 condition from each pair of samples. Following the standard procedure, however, we take samples from both conditions and use the smaller of the two observed sample means as the estimator. In some pairs of samples, we will correctly choose the sample mean from the 500 condition as the estimator, if this condition produces the smaller of the observed sample means. In other pairs of samples, however, we will incorrectly choose the sample mean from the 501 condition when it is smaller than the mean from the 500 condition. Thus, the standard procedure selects an unbiased value in some pairs of samples, but it selects a value that is smaller than the unbiased estimator in other pairs of samples. In the long run, across all pairs of samples, the standard procedure is therefore biased toward small values. The long run average of the sample means selected by the standard procedure will thus be less than $500 \mathrm{msec}$, thereby underestimating the true value being sought.

In the remainder of this article, we report computer simulations conducted with two goals. One goal was to estimate the amount of bias in the estimator defined as the smaller of two sample means or medians (referred to hereafter as the mean- or median-based standard estimator). This estimator has been commonly used, and it is therefore worthwhile to have some information about how much previous results may have been influenced by this bias. Bias is defined as the difference between the average long run value of the estimator and the true value being estimated, so that a negative bias indicates underestimation and a positive bias indicates overestimation.

The second goal was to search for a better (i.e., less biased) estimator. A number of estimators were constructed to try to improve on the standard one, and several much less biased-though still not unbiased-estimators were discovered. It was also found that some estimators overestimate the true value, unlike the standard estimator, which underestimates it. By combining two estimators biased in different directions, it is possible to construct a conservative interval estimate for the true value being sought.

\section{Bias in the Standard Estimators: \\ Computer Simulations}

To determine the amount of bias in the mean-based standard estimator, a series of computer simulations was carried out. A computer program simulated the collection of RTs in each of two experimental conditions by taking a pair of random samples, one from each of two distributions. Following the standard procedure, the mean of each sample was computed, and the smaller of the two sample means was selected as the estimate for the smaller of the two true condition means. To find the bias in this procedure, the program repeated the procedure 10,000 times, and the average value of the 10,000 estimates was computed. Bias was then computed as the difference between the true value of the smaller condition mean (fixed for the simulation run) and the average of the 10,000 standard estimates.

Each simulation run (i.e., 10,000 pairs of samples) was designed to determine the bias of this estimator under a specific set of experimental conditions. ${ }^{5}$ Experimental conditions were defined in terms of three parameters, and values of the parameters were chosen to reflect values typical of experiments in which this estimation procedure is used. One parameter that was varied across simulation runs was the number of trials per experimental condition, which took on values of $10,20,30,50,75$, and 100 . Another parameter was the standard deviation of the RT distribution within each condition $(25,50,75,100,200$, or $300 \mathrm{msec}$ ). In every simulation run, the two experimental conditions had the same standard deviation of RT and the same number of trials per condition. The third parameter was the separation between the true mean RTs of the two experimental conditions. The mean of the RT distribution for one experimental condition was arbitrarily set at $500 \mathrm{msec}$, since the absolute magnitude of the RTs does not influence the extent of the bias. The mean RT for the other experimental condition was set at 500 , $495,490,480$, or $450 \mathrm{msec}$, in order to vary the separation between means. There were 180 different simulation runs defined by different combinations of these parameter values $(6$ values of the number of trials per condition $x$ 5 values of the separation of means $\times 6$ values of the standard deviation of RT distributions).

Simulation runs also differed in the assumed shape of the underlying RT distribution in each condition. In one set of 180 simulation runs, RT distributions were assumed to be normal. In another set, they were assumed to be log-normal, so that the simulated RTs would have some positive skew, as is commonly found in observed RT distributions (e.g., McCormack \& Wright, 1964). We had no specific expectations about how the shape of the RT distribution would influence bias, but deemed it important to examine this question empirically.

Table 1 shows the average bias of the standard estimator as a function of the combinations of parameter values. Table 2 shows the results of an analogous set of simulations using medians rather than means. These simulations were conducted because many researchers use median rather than mean RT to summarize the data from a single subject and condition. The simulations were the same as those described above, with two exceptions. First, in each of the randomly generated samples, sample median rather than mean was computed, and the smaller of the two medians was selected as the value of the estimator. Second, bias was measured as the difference between the average value of the estimator, across simulations, and the smaller of the two true condition medians. 
Table 1

Bias in the Mean-Based Standard Estimator as a Function of Separation Between Means, Standard Deviation of Reaction Time (RT), Number of Trials, and Shape of the RT Distribution

\begin{tabular}{|c|c|c|c|c|c|c|}
\hline \multirow{2}{*}{$\begin{array}{c}\text { Trials } \\
\text { per } \\
\text { Condition }\end{array}$} & \multirow{2}{*}{$\begin{array}{c}\text { Standard } \\
\text { Deviation } \\
\text { of RT }\end{array}$} & \multicolumn{5}{|c|}{ Separation in True Means (in msec) } \\
\hline & & 0 & 5 & 10 & 20 & 50 \\
\hline \multicolumn{7}{|c|}{ Normal Distribution of RT } \\
\hline 10 & $\begin{array}{r}25 \\
50 \\
75 \\
100 \\
200 \\
300\end{array}$ & $\begin{array}{r}-4.402 \\
-8.848 \\
-13.505 \\
-18.005 \\
-35.878 \\
-54.436\end{array}$ & $\begin{array}{r}-2.423 \\
-6.791 \\
-11.115 \\
-15.737 \\
-33.417 \\
-51.869\end{array}$ & $\begin{array}{r}-1.247 \\
-4.870 \\
-9.095 \\
-13.365 \\
-31.076 \\
-49.196\end{array}$ & $\begin{array}{r}-0.268 \\
-2.142 \\
-5.901 \\
-9.788 \\
-26.728 \\
-44.941\end{array}$ & $\begin{array}{r}-0.097 \\
-0.301 \\
-1.110 \\
-3.092 \\
-16.241 \\
-32.417\end{array}$ \\
\hline 20 & $\begin{array}{r}25 \\
50 \\
75 \\
100 \\
200 \\
300\end{array}$ & $\begin{array}{r}-3.218 \\
-6.224 \\
-9.491 \\
-12.542 \\
-25.143 \\
-37.699\end{array}$ & $\begin{array}{r}-1.365 \\
-4.067 \\
-7.110 \\
-10.119 \\
-22.739 \\
-34.975\end{array}$ & $\begin{array}{r}-0.426 \\
-2.459 \\
-5.169 \\
-8.074 \\
-20.503 \\
-32.950\end{array}$ & $\begin{array}{r}-0.114 \\
-0.990 \\
-2.570 \\
-5.231 \\
-16.521 \\
-28.645\end{array}$ & $\begin{array}{r}0.024 \\
0.052 \\
-0.097 \\
-0.910 \\
-7.991 \\
-18.220\end{array}$ \\
\hline 30 & $\begin{array}{r}25 \\
50 \\
75 \\
100 \\
200 \\
300\end{array}$ & $\begin{array}{r}-2.513 \\
-5.188 \\
-7.806 \\
-10.463 \\
-20.971 \\
-31.385\end{array}$ & $\begin{array}{r}-0.912 \\
-3.108 \\
-5.619 \\
-8.123 \\
-18.522 \\
-28.902\end{array}$ & $\begin{array}{r}-0.206 \\
-1.642 \\
-3.844 \\
-6.152 \\
-16.264 \\
-26.608\end{array}$ & $\begin{array}{r}-0.024 \\
-0.548 \\
-1.555 \\
-3.375 \\
-12.314 \\
-22.265\end{array}$ & $\begin{array}{r}0.042 \\
-0.179 \\
-0.144 \\
-0.439 \\
-4.917 \\
-12.260\end{array}$ \\
\hline 50 & $\begin{array}{r}25 \\
50 \\
75 \\
100 \\
200 \\
300\end{array}$ & $\begin{array}{r}-2.061 \\
-4.070 \\
-6.042 \\
-8.034 \\
-15.992 \\
-24.107\end{array}$ & $\begin{array}{r}-0.436 \\
-1.920 \\
-3.703 \\
-5.847 \\
-13.625 \\
-21.684\end{array}$ & $\begin{array}{r}-0.037 \\
-0.922 \\
-2.431 \\
-4.050 \\
-11.505 \\
-19.323\end{array}$ & $\begin{array}{r}-0.059 \\
-0.137 \\
-0.781 \\
-1.710 \\
-7.943 \\
-15.425\end{array}$ & $\begin{array}{l}-0.013 \\
-0.026 \\
-0.203 \\
-0.273 \\
-2.100 \\
-6.745\end{array}$ \\
\hline 75 & $\begin{array}{r}25 \\
50 \\
75 \\
100 \\
200 \\
300\end{array}$ & $\begin{array}{r}-1.681 \\
-3.379 \\
-5.062 \\
-6.754 \\
-13.361 \\
-20.092\end{array}$ & $\begin{array}{r}-0.249 \\
-1.413 \\
-2.827 \\
-4.570 \\
-10.994 \\
-17.636\end{array}$ & $\begin{array}{r}-0.061 \\
-0.502 \\
-1.551 \\
-2.867 \\
-8.940 \\
-15.514\end{array}$ & $\begin{array}{r}-0.027 \\
-0.064 \\
-0.376 \\
-0.996 \\
-5.685 \\
-11.668\end{array}$ & $\begin{array}{l}-0.008 \\
-0.031 \\
-0.055 \\
-0.078 \\
-1.090 \\
-4.326\end{array}$ \\
\hline 100 & $\begin{array}{r}25 \\
50 \\
75 \\
100 \\
200 \\
300\end{array}$ & $\begin{array}{r}-1.484 \\
-2.877 \\
-4.306 \\
-5.769 \\
-11.217 \\
-16.872\end{array}$ & $\begin{array}{r}-0.213 \\
-1.058 \\
-2.354 \\
-3.600 \\
-8.892 \\
-14.448\end{array}$ & $\begin{array}{r}-0.070 \\
-0.289 \\
-1.252 \\
-2.059 \\
-7.171 \\
-12.256\end{array}$ & $\begin{array}{l}-0.035 \\
-0.157 \\
-0.149 \\
-0.543 \\
-3.935 \\
-8.666\end{array}$ & $\begin{array}{l}-0.059 \\
-0.124 \\
-0.066 \\
-0.039 \\
-0.483 \\
-2.471\end{array}$ \\
\hline \multicolumn{7}{|c|}{ Log-Normal Distribution of RT } \\
\hline 10 & $\begin{array}{r}25 \\
50 \\
75 \\
100 \\
200 \\
300\end{array}$ & $\begin{array}{r}-4.630 \\
-8.992 \\
-13.580 \\
-17.995 \\
-35.974 \\
-53.669\end{array}$ & $\begin{array}{r}-2.396 \\
-6.721 \\
-11.242 \\
-15.744 \\
-33.495 \\
-51.401\end{array}$ & $\begin{array}{r}-1.212 \\
-4.876 \\
-8.963 \\
-13.674 \\
-31.251 \\
-49.012\end{array}$ & $\begin{array}{r}-0.251 \\
-2.427 \\
-6.012 \\
-9.527 \\
-27.043 \\
-44.427\end{array}$ & $\begin{array}{r}-0.054 \\
-0.272 \\
-1.083 \\
-3.050 \\
-16.477 \\
-32.695\end{array}$ \\
\hline 20 & $\begin{array}{r}25 \\
50 \\
75 \\
100 \\
200 \\
300\end{array}$ & $\begin{array}{r}-3.125 \\
-6.274 \\
-9.454 \\
-13.028 \\
-25.128 \\
-37.568\end{array}$ & $\begin{array}{r}-1.282 \\
-4.109 \\
-7.327 \\
-10.479 \\
-22.627 \\
-35.215\end{array}$ & $\begin{array}{r}-0.452 \\
-2.559 \\
-5.462 \\
-8.272 \\
-20.448 \\
-32.887\end{array}$ & $\begin{array}{r}0.001 \\
-0.907 \\
-2.704 \\
-5.128 \\
-16.431 \\
-28.157\end{array}$ & $\begin{array}{r}-0.074 \\
-0.053 \\
-0.315 \\
-0.971 \\
-7.725 \\
-18.145\end{array}$ \\
\hline 30 & $\begin{array}{r}25 \\
50 \\
75 \\
100 \\
200 \\
300\end{array}$ & $\begin{array}{r}-2.591 \\
-5.218 \\
-7.812 \\
-10.530 \\
-21.125 \\
-31.642\end{array}$ & $\begin{array}{r}-0.853 \\
-3.097 \\
-5.779 \\
-8.134 \\
-18.746 \\
-29.155\end{array}$ & $\begin{array}{r}-0.257 \\
-1.733 \\
-3.952 \\
-6.415 \\
-16.349 \\
-26.892\end{array}$ & $\begin{array}{r}-0.042 \\
-0.347 \\
-1.816 \\
-3.578 \\
-12.491 \\
-22.429\end{array}$ & $\begin{array}{r}-0.048 \\
-0.031 \\
-0.264 \\
-0.628 \\
-4.862 \\
-13.193\end{array}$ \\
\hline 50 & $\begin{array}{c}25 \\
50\end{array}$ & $\begin{array}{l}-1.968 \\
-4.153\end{array}$ & $\begin{array}{l}-0.455 \\
-2.006\end{array}$ & $\begin{array}{l}-0.069 \\
-0.919\end{array}$ & $\begin{array}{l}-0.064 \\
-0.232\end{array}$ & $\begin{array}{l}-0.020 \\
-0.136\end{array}$ \\
\hline
\end{tabular}


Table 1 (Continued)

\begin{tabular}{|c|c|c|c|c|c|c|}
\hline \multirow{2}{*}{$\begin{array}{c}\text { Trials } \\
\text { per } \\
\text { Condition } \\
\end{array}$} & \multirow{2}{*}{$\begin{array}{c}\text { Standard } \\
\text { Deviation } \\
\text { of RT }\end{array}$} & \multicolumn{5}{|c|}{ Separation in True Means (in msec) } \\
\hline & & 0 & 5 & 10 & 20 & 50 \\
\hline & $\begin{array}{r}75 \\
100 \\
200 \\
300\end{array}$ & $\begin{array}{r}-6.234 \\
-8.141 \\
-16.124 \\
-24.235\end{array}$ & $\begin{array}{r}-3.735 \\
-5.953 \\
-13.809 \\
-21.930\end{array}$ & $\begin{array}{r}-2.422 \\
-4.149 \\
-11.598 \\
-19.675\end{array}$ & $\begin{array}{r}-0.900 \\
-1.881 \\
-8.143 \\
-15.629\end{array}$ & $\begin{array}{r}-0.213 \\
-0.051 \\
-2.229 \\
-7.238\end{array}$ \\
\hline 75 & $\begin{array}{r}25 \\
50 \\
75 \\
100 \\
200 \\
300\end{array}$ & $\begin{array}{r}-1.671 \\
-3.310 \\
-5.092 \\
-6.671 \\
-13.440 \\
-20.193\end{array}$ & $\begin{array}{r}-0.296 \\
-1.500 \\
-2.839 \\
-4.428 \\
-11.091 \\
-17.764\end{array}$ & $\begin{array}{r}-0.028 \\
-0.476 \\
-1.568 \\
-2.865 \\
-9.074 \\
-15.587\end{array}$ & $\begin{array}{r}-0.047 \\
-0.138 \\
-0.488 \\
-1.175 \\
-5.773 \\
-11.920\end{array}$ & $\begin{array}{r}-0.014 \\
-0.170 \\
-0.039 \\
-0.139 \\
-1.312 \\
-4.853\end{array}$ \\
\hline
\end{tabular}

Table 2

Bias in the Median-Based Standard Estimator as a Function of Separation Between Means, Standard Deviation of Reaction Time (RT), Number of Trials, and Shape of the RT Distribution

\begin{tabular}{|c|c|c|c|c|c|c|}
\hline \multirow{2}{*}{$\begin{array}{c}\text { Trials } \\
\text { per } \\
\text { Condition }\end{array}$} & \multirow{2}{*}{$\begin{array}{c}\text { Standard } \\
\text { Deviation } \\
\text { of RT }\end{array}$} & \multicolumn{5}{|c|}{ Separation in True Means (in msec) } \\
\hline & & 0 & 5 & 10 & 20 & 50 \\
\hline \multicolumn{7}{|c|}{ Normal Distribution of RT } \\
\hline 10 & $\begin{array}{r}25 \\
50 \\
75 \\
100 \\
200 \\
300\end{array}$ & $\begin{array}{r}-5.388 \\
-10.775 \\
-15.614 \\
-20.744 \\
-41.952 \\
-62.928\end{array}$ & $\begin{array}{r}-3.138 \\
-8.093 \\
-13.283 \\
-18.415 \\
-39.479 \\
-60.439\end{array}$ & $\begin{array}{r}-1.693 \\
-6.637 \\
-11.251 \\
-16.329 \\
-36.829 \\
-57.588\end{array}$ & $\begin{array}{r}-0.436 \\
-3.634 \\
-7.791 \\
-12.229 \\
-32.394 \\
-53.337\end{array}$ & $\begin{array}{r}0.014 \\
-0.397 \\
-1.825 \\
-4.686 \\
-21.770 \\
-41.206\end{array}$ \\
\hline 20 & $\begin{array}{r}25 \\
50 \\
75 \\
100 \\
200 \\
300\end{array}$ & $\begin{array}{r}-3.715 \\
-7.491 \\
-11.479 \\
-15.450 \\
-29.944 \\
-44.916\end{array}$ & $\begin{array}{r}-1.849 \\
-5.432 \\
-8.838 \\
-12.888 \\
-27.542 \\
-42.491\end{array}$ & $\begin{array}{r}-0.651 \\
-3.658 \\
-7.176 \\
-10.294 \\
-25.427 \\
-40.398\end{array}$ & $\begin{array}{r}-0.041 \\
-1.416 \\
-4.196 \\
-7.252 \\
-21.257 \\
-35.939\end{array}$ & $\begin{array}{r}-0.007 \\
0.161 \\
-0.465 \\
-1.943 \\
-11.482 \\
-24.561\end{array}$ \\
\hline 30 & $\begin{array}{r}25 \\
50 \\
75 \\
100 \\
200 \\
300\end{array}$ & $\begin{array}{r}-3.238 \\
-6.319 \\
-9.638 \\
-12.625 \\
-25.317 \\
-37.975\end{array}$ & $\begin{array}{r}-1.417 \\
-4.097 \\
-7.419 \\
-10.698 \\
-22.840 \\
-35.471\end{array}$ & $\begin{array}{r}-0.404 \\
-2.496 \\
-5.717 \\
-8.547 \\
-20.624 \\
-33.213\end{array}$ & $\begin{array}{r}-0.082 \\
-0.972 \\
-2.999 \\
-5.255 \\
-16.493 \\
-29.282\end{array}$ & $\begin{array}{r}-0.021 \\
-0.170 \\
-0.206 \\
-1.095 \\
-8.525 \\
-18.872\end{array}$ \\
\hline 50 & $\begin{array}{r}25 \\
50 \\
75 \\
100 \\
200 \\
300\end{array}$ & $\begin{array}{r}-2.476 \\
-5.058 \\
-7.415 \\
-9.903 \\
-19.387 \\
-29.080\end{array}$ & $\begin{array}{r}-0.745 \\
-2.898 \\
-5.221 \\
-7.586 \\
-16.981 \\
-26.638\end{array}$ & $\begin{array}{r}-0.164 \\
-1.714 \\
-3.458 \\
-5.664 \\
-14.830 \\
-24.416\end{array}$ & $\begin{array}{r}-0.061 \\
-0.294 \\
-1.366 \\
-2.872 \\
-11.001 \\
-20.302\end{array}$ & $\begin{array}{r}-0.036 \\
0.039 \\
-0.020 \\
-0.067 \\
-3.993 \\
-10.940\end{array}$ \\
\hline 75 & $\begin{array}{r}25 \\
50 \\
75 \\
100 \\
200 \\
300\end{array}$ & $\begin{array}{r}-2.045 \\
-4.099 \\
-6.131 \\
-8.177 \\
-16.783 \\
-25.174\end{array}$ & $\begin{array}{r}-0.406 \\
-2.071 \\
-3.860 \\
-5.858 \\
-14.367 \\
-22.630\end{array}$ & $\begin{array}{r}-0.038 \\
-0.929 \\
-2.241 \\
-4.223 \\
-12.231 \\
-20.465\end{array}$ & $\begin{array}{r}-0.030 \\
-0.104 \\
-0.715 \\
-1.725 \\
-8.621 \\
-16.598\end{array}$ & $\begin{array}{r}0.008 \\
-0.080 \\
-0.123 \\
-0.067 \\
-2.942 \\
-8.195\end{array}$ \\
\hline 100 & $\begin{array}{r}25 \\
50 \\
75 \\
100 \\
200 \\
300\end{array}$ & $\begin{array}{r}-1.802 \\
-3.515 \\
-5.378 \\
-7.112 \\
-13.802 \\
-21.647\end{array}$ & $\begin{array}{r}-0.338 \\
-1.594 \\
-3.222 \\
-4.918 \\
-11.480 \\
-18.981\end{array}$ & $\begin{array}{r}-0.049 \\
-0.607 \\
-1.872 \\
-3.169 \\
-9.464 \\
-16.927\end{array}$ & $\begin{array}{r}0.002 \\
-0.024 \\
-0.379 \\
-1.111 \\
-6.165 \\
-12.888\end{array}$ & $\begin{array}{r}0.001 \\
-0.001 \\
0.015 \\
-0.023 \\
-1.017 \\
-4.546\end{array}$ \\
\hline
\end{tabular}


Table 2 (Continued)

\begin{tabular}{|c|c|c|c|c|c|c|}
\hline \multirow{2}{*}{$\begin{array}{c}\text { Trials } \\
\text { per } \\
\text { Condition }\end{array}$} & \multirow{2}{*}{$\begin{array}{c}\text { Standard } \\
\text { Deviation } \\
\text { of RT }\end{array}$} & \multicolumn{5}{|c|}{ Separation in True Means (in msec) } \\
\hline & & 0 & 5 & 10 & 20 & 50 \\
\hline \multicolumn{7}{|c|}{ Log Normal Distribution of RT } \\
\hline 10 & $\begin{array}{r}25 \\
50 \\
75 \\
100 \\
200 \\
300\end{array}$ & $\begin{array}{r}-5.239 \\
-9.973 \\
-14.547 \\
-19.275 \\
-31.957 \\
-39.675\end{array}$ & $\begin{array}{r}-2.980 \\
-7.647 \\
-12.096 \\
-16.850 \\
-29.301 \\
-36.902\end{array}$ & $\begin{array}{r}-1.607 \\
-5.791 \\
-10.417 \\
-14.173 \\
-26.770 \\
-34.275\end{array}$ & $\begin{array}{r}-0.282 \\
-3.235 \\
-6.886 \\
-10.144 \\
-22.058 \\
-29.349\end{array}$ & $\begin{array}{r}0.036 \\
0.037 \\
-0.912 \\
-2.713 \\
-10.745 \\
-15.811\end{array}$ \\
\hline 20 & $\begin{array}{r}25 \\
50 \\
75 \\
100 \\
200 \\
300\end{array}$ & $\begin{array}{r}-3.648 \\
-7.387 \\
-10.821 \\
-13.803 \\
-24.299 \\
-30.776\end{array}$ & $\begin{array}{r}-1.784 \\
-5.107 \\
-8.639 \\
-11.193 \\
-21.722 \\
-28.031\end{array}$ & $\begin{array}{r}-0.716 \\
-3.521 \\
-6.336 \\
-9.461 \\
-19.323 \\
-25.787\end{array}$ & $\begin{array}{r}-0.074 \\
-1.091 \\
-3.344 \\
-6.001 \\
-15.045 \\
-20.717\end{array}$ & $\begin{array}{r}0.058 \\
0.187 \\
-0.018 \\
-0.757 \\
-5.615 \\
-9.746\end{array}$ \\
\hline 30 & $\begin{array}{r}25 \\
50 \\
75 \\
100 \\
200 \\
300\end{array}$ & $\begin{array}{r}-3.199 \\
-6.035 \\
-9.395 \\
-11.593 \\
-20.925 \\
-26.829\end{array}$ & $\begin{array}{r}-1.182 \\
-4.137 \\
-6.918 \\
-9.672 \\
-18.311 \\
-24.193\end{array}$ & $\begin{array}{r}-0.517 \\
-2.504 \\
-4.697 \\
-7.215 \\
-15.907 \\
-21.810\end{array}$ & $\begin{array}{r}-0.029 \\
-0.550 \\
-2.448 \\
-4.458 \\
-11.670 \\
-16.699\end{array}$ & $\begin{array}{l}-0.121 \\
-0.175 \\
-0.290 \\
-0.684 \\
-3.181 \\
-6.339\end{array}$ \\
\hline 50 & $\begin{array}{r}25 \\
50 \\
75 \\
100 \\
200 \\
300\end{array}$ & $\begin{array}{r}-2.455 \\
-4.945 \\
-7.110 \\
-9.252 \\
-16.313 \\
-21.223\end{array}$ & $\begin{array}{r}-0.752 \\
-2.734 \\
-4.829 \\
-6.971 \\
-13.762 \\
-18.569\end{array}$ & $\begin{array}{r}-0.145 \\
-1.436 \\
-3.143 \\
-5.311 \\
-11.471 \\
-16.196\end{array}$ & $\begin{array}{r}-0.036 \\
-0.217 \\
-1.265 \\
-2.350 \\
-7.632 \\
-11.621\end{array}$ & $\begin{array}{r}-0.008 \\
0.028 \\
0.085 \\
0.073 \\
-1.011 \\
-2.952\end{array}$ \\
\hline 75 & $\begin{array}{r}25 \\
50 \\
75 \\
100 \\
200 \\
300\end{array}$ & $\begin{array}{r}-2.043 \\
-4.094 \\
-5.808 \\
-7.935 \\
-14.220 \\
-18.677\end{array}$ & $\begin{array}{r}-0.457 \\
-1.925 \\
-3.705 \\
-5.503 \\
-11.666 \\
-16.070\end{array}$ & $\begin{array}{r}-0.001 \\
-0.882 \\
-2.386 \\
-3.935 \\
-9.393 \\
-13.644\end{array}$ & $\begin{array}{l}-0.020 \\
-0.248 \\
-0.652 \\
-1.348 \\
-5.880 \\
-9.363\end{array}$ & $\begin{array}{r}0.054 \\
0.134 \\
0.240 \\
0.332 \\
-0.773 \\
-1.994\end{array}$ \\
\hline 100 & $\begin{array}{r}25 \\
50 \\
75 \\
100 \\
200 \\
300\end{array}$ & $\begin{array}{r}-1.779 \\
-3.384 \\
-5.210 \\
-6.702 \\
-12.243 \\
-15.424\end{array}$ & $\begin{array}{r}-0.259 \\
-1.596 \\
-3.051 \\
-4.544 \\
-9.732 \\
-12.779\end{array}$ & $\begin{array}{r}-0.068 \\
-0.606 \\
-1.604 \\
-2.631 \\
-7.667 \\
-10.476\end{array}$ & $\begin{array}{r}0.011 \\
-0.068 \\
-0.341 \\
-0.848 \\
-4.280 \\
-7.156\end{array}$ & $\begin{array}{l}-0.049 \\
-0.077 \\
-0.082 \\
-0.071 \\
-0.028 \\
-0.626\end{array}$ \\
\hline
\end{tabular}

Clearly, both the mean- and median-based standard estimators consistently underestimate the true values they are intended to estimate. The overall bias is usually fairly small, being under $20 \mathrm{msec}$ in most cases. With some combinations of parameters, however, bias exceeds $50 \mathrm{msec}$. Figure 1 illustrates the highly regular pattern of bias as a function of the degree of separation between means and the standard error of the mean.

It is worthwhile to consider the large influence of the simulation parameters on the amount of bias. As described above, bias enters the estimation procedure because the sample mean from the desired condition (e.g., 500) is $0 c-$ casionally larger, by chance, than the sample mean from the other condition (e.g., 501). When this happens, the standard procedure selects the wrong sample mean as the estimate; in fact, it selects a sample mean smaller than the one it should select. In general, bias should be larger under experimental conditions in which the standard procedure is more likely to select a too-small sample mean by chance.

In terms of the simulation parameters, the preceding argument implies that bias should be larger when the difference in true condition means is smaller, because a smaller difference in true means provides more opportunity for the sample mean from the larger condition to be smaller by chance. The results in Tables 1 and 2 clearly confirm this expectation. Bias should also be larger when sampling error is larger, because a larger sampling error provides more opportunity for accidental reversals. Sampling error is determined by the number of trials per condition and the standard deviation of the RT distributions in each condition, according to the well-known formula that the standard error of the mean is equal to the standard deviation divided by the square root of sample size (Hays, 1973). Thus, bias should be larger when the standard deviation of RT is larger and when sample size is 


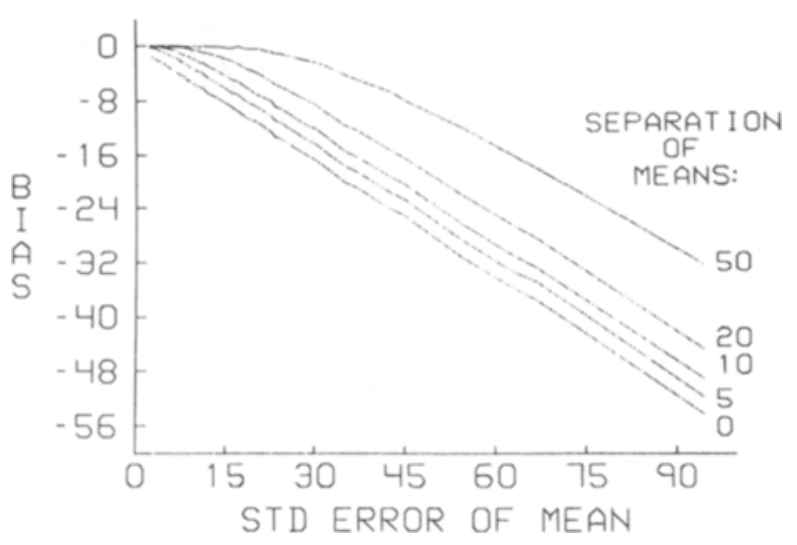

Figure 1. Average bias of the mean-based standard estimator as a function of simulation parameters. Standard error of the mean is the standard deviation of the reaction time (RT) distributions divided by the square root of the sample size $(10,20,30,50,75$, or 100). The parameter labeling the curves is the separation between true means of the two RT distributions $(0,5,10,20$, or 50 msec).

smaller. This expectation is most clearly confirmed in Figure 1.

\section{Other Estimators}

In the hope of finding a better estimator of the smaller of two means (medians) than the standard one, we also examined the behavior of 15 other estimators. Values of each of these estimators were computed in the same simulation runs used to evaluate the standard estimator. The average value of each of these estimators was computed across the 10,000 pairs of samples within each run. The bias of each estimator was then ascertained just as it had been for the standard estimator: by subtracting the known value of the smaller true mean.

The 15 alternative estimators are described in the Appendix. Basically, we generated estimators to span classes that seemed intuitively promising to us, but of course we cannot be sure that there is no other estimator better than any we tried. For most practical purposes, the reader will probably want to know only about the estimator that turned out to be the best: the all-or-none estimator with a $p$ level of .10. This estimator can be calculated as follows: For each subject, first do a standard analysis of variance or $t$ test to test the null hypothesis that there is no difference in averages for the two control conditions. Use a critical value based on a $p$ value of .10. Then, the value of the estimator for that subject is the smaller of the two means if the null hypothesis is rejected, and it is the average of the two means if the null hypothesis is not rejected. Across subjects, values of the estimator can be analyzed just as one analyzes the smaller of the two means obtained from the standard estimation procedure.

For each of the 15 new estimators, bias was computed at each of the 180 combinations of parameter values, just as it was for the standard estimator. Since it is not practical to present the complete results (i.e., tables analogous to Tables 1 and 2) for each estimator, the performance of each estimator was summarized across conditions, and the summaries are presented in Table 3. The leftmost column of the table shows a measure of the overall bias of each estimator: root mean square bias (RMSB). This value was obtained by taking the square root of the average of the 180 squared biases. It is a reasonable measure of the overall bias associated with each estimator, and it weights larger biases more heavily than smaller biases, following the precedent of least squared error estimation. Note that this is a directionless quantity, measuring only degree of bias, not underestimation versus overestimation. In a sense, RMSB is analogous to the more familiar root mean square error, except that it measures systematic error across conditions (bias) rather than random error.

In overall bias of estimation, the standard estimator was one of the worst of the 16 tried. Across the conditions of the simulation, its RMSB was about $15 \mathrm{msec}$. Other estimators had as little as one-third as much bias.

Inspection of figures analogous to Figure 1 for all 16 estimators with both normal and log-normal distributions of RT revealed a high degree of consistency in the overall shapes of the graphs. In all cases, estimators were very nearly unbiased when standard error of the mean was small, and the lines corresponding to different separations of means fanned out as the standard error of the mean increased. That is, the left side of the fan was near zero on all graphs. Some graphs fanned out almost entirely below zero (e.g., the standard estimator); some, almost entirely above zero; and some, more or less symmetrically around zero. Also, the fans differed somewhat in overall separation at the right edge of the graphs. It is therefore possible to summarize each graph reasonably accurately by reporting the top and bottom of the fan on the right side of the graph. These points correspond to biases in the two conditions with the largest and the smallest separations of means, in simulations with the largest standard error (smallest sample size and largest variance). The former is the condition in which each estimator had its maximum overestimate (i.e., largest overestimate or smallest absolute underestimate), and the latter is the condition in which each estimator had its maximum underestimate (i.e., largest absolute underestimate or smallest overestimate). The second and third columns in Table 3 display these values for each estimator. The larger of these two numbers, in absolute value, is the worst case bias of the estimator, in the sense of being the greatest absolute bias we observed with that estimator.

Based on the biases of the various estimators, we would recommend the all-or-none estimator with a critical $p$ level of .10 as the single best overall estimator of the smaller of two means (medians). This estimator has one of the smallest overall RMSBs, averaging across the conditions of the simulations, in both mean- and median-based estimations for both normal and log-normal RT distributions. ${ }^{6}$ Furthermore, it has a worst case bias that is consistently among the best of all the estimators.

We conducted a further analysis to make sure that the all-or-none estimator with $p$ of .10 is not simply one of the best overall, but is also one of the best under any 
Table 3

Summary Measures of Bias for the 16 Estimators Examined

\begin{tabular}{|c|c|c|c|c|c|c|}
\hline \multirow[b]{2}{*}{ Estimator } & \multicolumn{3}{|c|}{ Normal RT } & \multicolumn{3}{|c|}{ Log-Normal RT } \\
\hline & RMSB & $\begin{array}{r}\text { Maximum } \\
\text { Overestimate }\end{array}$ & $\begin{array}{r}\text { Maximum } \\
\text { underestimate }\end{array}$ & RMSB & $\begin{array}{r}\text { Maximum } \\
\text { Overestimate }\end{array}$ & $\begin{array}{r}\text { Maximum } \\
\text { Underestimate }\end{array}$ \\
\hline \multicolumn{7}{|c|}{ Mean-Based Estimation } \\
\hline Standard & 13.826 & -32.417 & -54.436 & 12.961 & -32.695 & -53.669 \\
\hline $\begin{array}{c}\text { All-or-None } \\
p<.01 \\
p<.05 \\
p<.10 \\
p<.25\end{array}$ & $\begin{array}{l}7.292 \\
4.986 \\
4.108 \\
6.216\end{array}$ & $\begin{array}{r}+21.758 \\
+14.752 \\
+7.771 \\
-6.494\end{array}$ & $\begin{array}{r}-2.808 \\
-8.243 \\
-14.280 \\
-28.168\end{array}$ & $\begin{array}{l}7.335 \\
4.714 \\
3.412 \\
5.394\end{array}$ & $\begin{array}{r}+21.840 \\
+15.011 \\
+7.259 \\
-8.087\end{array}$ & $\begin{array}{r}-2.540 \\
-7.142 \\
-12.623 \\
-27.500\end{array}$ \\
\hline$P$-Weighted Average & 9.119 & -16.634 & -38.518 & 8.269 & -17.452 & -37.978 \\
\hline 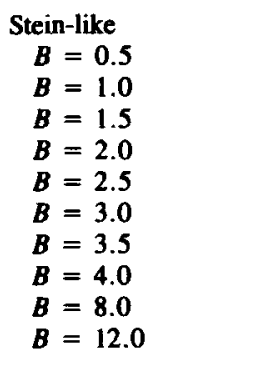 & $\begin{array}{l}8.602 \\
6.865 \\
5.995 \\
5.551 \\
5.351 \\
5.295 \\
5.325 \\
5.428 \\
6.408 \\
7.216\end{array}$ & $\begin{array}{r}-14.853 \\
-8.016 \\
-3.660 \\
-0.524 \\
+1.883 \\
+3.808 \\
+5.394 \\
+6.728 \\
+12.870 \\
+15.734\end{array}$ & $\begin{array}{r}-36.875 \\
-30.250 \\
-26.088 \\
-23.122 \\
-20.863 \\
-19.068 \\
-17.597 \\
-16.365 \\
-10.767 \\
-8.200\end{array}$ & $\begin{array}{l}7.756 \\
6.008 \\
5.149 \\
4.749 \\
4.613 \\
4.627 \\
4.725 \\
4.867 \\
6.154 \\
7.067\end{array}$ & $\begin{array}{r}-15.680 \\
-8.833 \\
-4.428 \\
-1.246 \\
+1.204 \\
+3.166 \\
+4.782 \\
+6.142 \\
+12.389 \\
+15.284\end{array}$ & $\begin{array}{r}-36.439 \\
-29.792 \\
-25.623 \\
-22.620 \\
-20.417 \\
-18.639 \\
-17.189 \\
-15.979 \\
-10.542 \\
-8.093\end{array}$ \\
\hline \multicolumn{7}{|c|}{ Median-Based Estimation } \\
\hline Standard & 16.888 & -41.206 & -62.928 & 11.560 & -15.811 & -39.675 \\
\hline $\begin{array}{c}\text { All-or-None } \\
p<.01 \\
p<.05 \\
p<.10 \\
p<.25\end{array}$ & $\begin{array}{l}7.312 \\
4.952 \\
4.098 \\
6.176\end{array}$ & $\begin{array}{r}+21.391 \\
+14.338 \\
+7.904 \\
-6.797\end{array}$ & $\begin{array}{r}-2.370 \\
-8.377 \\
-14.091 \\
-27.170\end{array}$ & $\begin{array}{l}9.307 \\
6.860 \\
5.210 \\
3.871\end{array}$ & $\begin{array}{l}+35.962 \\
+29.880 \\
+24.232 \\
+11.967\end{array}$ & $\begin{array}{r}+9.564 \\
+4.989 \\
+0.014 \\
-10.896\end{array}$ \\
\hline$P$-Weighted Average & 9.739 & -18.668 & -39.890 & 5.777 & +2.949 & -20.569 \\
\hline $\begin{aligned} \text { Stein-like } \\
$\[ B=0.5 \]$ \\
B=1.0 \\
B=1.5 \\
B=2.0 \\
B=2.5 \\
B=3.0 \\
B=3.5 \\
B=4.0 \\
B=8.0 \\
B=12.0\end{aligned}$ & $\begin{array}{l}9.050 \\
7.101 \\
6.127 \\
5.625 \\
5.389 \\
5.311 \\
5.328 \\
5.400 \\
6.399 \\
7.216 \\
\end{array}$ & $\begin{array}{r}-16.435 \\
-9.048 \\
-4.450 \\
-1.176 \\
+1.323 \\
+3.314 \\
+4.949 \\
+6.322 \\
+12.618 \\
+15.545 \\
\end{array}$ & $\begin{array}{r}-37.787 \\
-30.662 \\
-26.307 \\
-23.242 \\
-20.926 \\
-19.094 \\
-17.599 \\
-16.350 \\
-10.703 \\
-8.125 \\
\end{array}$ & $\begin{array}{l}5.368 \\
4.546 \\
4.549 \\
4.821 \\
5.165 \\
5.513 \\
5.843 \\
6.148 \\
7.840 \\
8.797 \\
\end{array}$ & $\begin{array}{r}+4.840 \\
+10.782 \\
+14.500 \\
+17.159 \\
+19.194 \\
+20.819 \\
+22.155 \\
+23.279 \\
+28.439 \\
+30.836 \\
\end{array}$ & $\begin{array}{r}-18.820 \\
-13.149 \\
-9.680 \\
-7.238 \\
-5.389 \\
-3.927 \\
-2.734 \\
-1.738 \\
+2.758 \\
+4.799 \\
\end{array}$ \\
\hline
\end{tabular}

Note-RMSB = root mean square bias.

specific set of experimental conditions. For each of the four conditions of RT distribution shape (normal/lognormal) and type of statistic (mean/median), we conducted another analysis in which we computed RMSB separately for each of the 36 combinations of number of trials and standard deviation of RT. This RMSB was pooled across the different true separations of means, which are unknown in any practical application. In all of the $36 \times$ 4 cases, the all-or-none estimator with a $p$ value of .10 had the smallest or nearly the smallest RMSB. Thus, regardless of the number of trials or standard deviation of RT in an experiment, this estimator is one of the best.

\section{Variability of Estimators}

Based on the amount of bias in the various estimators, it seems clear that the standard estimator is not the best one. However, an additional consideration is the variability of each estimator: the extent to which its values fluctuate randomly from sample to sample. Under some circumstances, a more biased estimator might be preferred to a less biased one, if the more biased one were much less variable.

Table 4 shows the standard deviations of the 16 different estimators examined in these simulations, pooled across the 180 sets of parameter values. ${ }^{7}$ It is apparent from the values in the table that the estimators were quite similar to one another in overall variability. Further analyses indicated that the estimators were also quite similar in variability within each of the combinations of standard deviation of RT and sample size. Thus, it seems that in this case variability is less important than bias in choosing an estimator. Within the 180 conditions, of course, 
Table 4

Pooled Standard Deviations (in msec) of the 16 Different Estimators

\begin{tabular}{lcccc}
\hline & \multicolumn{2}{c}{ Mean-Based } & & \multicolumn{2}{c}{ Median-Based } \\
\cline { 2 - 3 } \cline { 5 - 6 } Estimator & Normal & Log-Normal & Normal & Log-Normal \\
\hline Standard & 25.69 & 23.90 & 30.91 & 24.73 \\
All-or-None & & & & \\
$p<.01$ & 23.36 & 23.05 & 27.59 & 23.52 \\
$p<.05$ & 25.28 & 24.87 & 29.49 & 24.79 \\
$p<.10$ & 26.45 & 25.91 & 30.70 & 25.56 \\
$p<.25$ & 27.57 & 26.72 & 32.13 & 26.35 \\
$P$-Weighted Average & 25.95 & 24.65 & 30.70 & 24.85 \\
Stein-like & & & & \\
$B=0.5$ & 25.60 & 24.35 & 30.38 & 24.64 \\
$B=1.0$ & 25.06 & 23.99 & 29.65 & 24.20 \\
$B=1.5$ & 24.62 & 23.67 & 29.13 & 23.87 \\
$B=2.0$ & 24.27 & 23.41 & 28.73 & 23.63 \\
$B=2.5$ & 23.98 & 23.19 & 28.42 & 23.44 \\
$B=3.0$ & 23.75 & 23.01 & 28.16 & 23.29 \\
$B=3.5$ & 23.55 & 22.86 & 27.95 & 23.16 \\
$B=4.0$ & 23.39 & 22.73 & 27.78 & 23.06 \\
$B=8.0$ & 22.59 & 22.14 & 26.98 & 22.61 \\
$B=12.0$ & 22.25 & 21.89 & 26.63 & 22.44 \\
\hline
\end{tabular}

variability for each estimator varied dramatically as a function of the standard error of the mean in each condition (i.e., as a function of number of trials and standard deviation of RT).

Unfortunately, the all-or-none estimator with a $p$ value of .10-which was preferred for its low bias-was one of the most variable. The increased variability was slight, fortunately, and it could be compensated for in practice by an increase of about $30 \%$ in the number of trials per condition, relative to the standard estimator. It is probably worthwhile to pay the price of slightly more variability to get a less biased estimator, because RT data are not difficult to collect and the bias directly interferes with the desired hypothesis test.

\section{Interval Estimates and Bounds}

As shown in Table 3, a few estimators tended to overestimate the true mean (median) rather than to underestimate it. For example, the all-or-none estimator with a $p$ level of .01 never underestimated the true mean by more than $3 \mathrm{msec}$, although its maximum overestimates were quite large. This suggests that one could use two estimators simultaneously to provide an interval estimate of the true value. A particularly good combination seems to be the standard estimator and the all-or-none estimator with a $p$ value of .01 . The former always underestimates the true value, and the latter almost always overestimates it. Because these estimators are biased in opposite directions, the true value should usually fall between them. This interval would be fairly conservative, unfortunately, because the worst case biases of both estimators are fairly large.

In practice, many investigators may want to use only one bound, depending on the purpose for which they are estimating the smaller of two means. If the experimental goal were to show that the smaller of two values is espe- cially small, perhaps relative to some comparison figure, then an estimator biased in the positive direction should be used (e.g., all-or-none with $p=.01$ ). This would be a conservative procedure, and the investigators could be confident that the smaller of two values was at least as small as they had estimated. Conversely, if the goal were to show that the smaller of two values is especially large, then an estimator biased in the negative direction should be used (e.g., standard estimator).

\section{General Discussion}

The statistical simulations presented here provide considerable guidance for those wishing to estimate the smaller of two true means, especially for the purpose of testing subject-by-subject race models. The estimator most commonly used in previous research is seriously biased, tending to underestimate the desired value by a substantial amount under some circumstances. Although we have not been able to construct an unbiased estimator, we have been able to identify an estimator that does quite a bit better than the standard estimator. In light of this, the standard estimator should not be used, except perhaps for comparison with previous reports using the same biased procedure.

The simulations presented here have addressed bias in estimation at the level of the individual subject. At the level of the experiment as a whole, the overall bias is simply the average of the biases for the individual subjects. This is an especially bad feature of the standard estimator, which is virtually always biased in the same direction. It means that the experiment as a whole will be biased, even if only a few of the individual subjects are biased. ${ }^{8}$

The bias in the standard estimator may have led directly to the conclusions of some previous investigators. Under particular suspicion are reports that a certain experimental condition was no faster than the faster of two control conditions. Since the bias in the standard estimator effectively reduces the comparison value obtained from the two control conditions, a true advantage for the experimental condition may have been concealed. Thus, the bias works to favor the subject-by-subject race model against alternative models in which the two processes interact to produce faster responses in the experimental condition than in the faster of the two control conditions (e.g., coactivation models; Miller, 1982).

To cite one recent example, Callaghan et al. (1986) compared discrimination of stimuli varying redundantly in hue and orientation with the faster of the two singledimension discriminations, and the faster of the two single-dimension means was estimated using the standard estimator. With some hues and orientations, no advantage was observed for the redundant condition, but it is possible that the bias in the standard estimator was enough to overcome a true advantage in the redundant condition.

It is, unfortunately, impossible to tell for certain how much bias was introduced by the standard estimator in any particular previous paper. Investigators do not typically report measures of the variability of RT within each 
condition (e.g., average standard deviation or standard error). Since this variability is a crucial determinant of the extent of bias, we can only guess at the bias in previous results. Based on results in our own laboratory, however, we would expect standard deviations to be at or near the high end of the values used in our simulations. In a systematic examination of representative experiments conducted in our lab over the past several years, we have found that the standard deviation of RT within subject and condition ranges from about 60 to $380 \mathrm{msec}$.

It is important to note that the bias in the standard estimator is largest when the two single-dimension conditions have equal means. Many investigators have sought to equate their single dimensions to provide the greatest opportunity for dimensions to interact (e.g., Garner, 1983; Pomerantz \& Sager, 1975; but see Garner, 1969). This is certainly a reasonable experimental procedure, because dimensions cannot interact unless they are recognized at about the same time (i.e., are equally discriminable). The consequence of this experimental procedure, however, is that the standard estimator is most commonly used under precisely the conditions in which it is most biased.

As an aside, this article emphasizes the utility of reporting some measure of the variability of RT within each condition, in addition to reporting a measure of central tendency. Variability can be relevant not only to models of specific tasks (e.g., Schneider \& Shiffrin, 1977), but also to an evaluation of statistical techniques that were used. In the present case, such measures would have been invaluable in estimating the probable influence of bias on conclusions of earlier experimental reports.

One might consider other slightly different experimental designs to try to circumvent the estimation problem considered here. Biederman and Checkosky (1970), for example, sought to find out whether a redundant-dimension judgment was faster than the smaller of the two singledimension judgments. They tested each subject twice in the redundant-dimension condition and compared the smaller of the two redundant-dimension averages against the smaller of the two single-dimension averages. On the surface, this appears to be an appropriate procedure, since each of the two values being compared is the smaller of two sample values. In fact, this procedure is very likely to be biased in favor of the redundant-dimension condition. Bias introduced into the redundant-dimension estimator would be relatively large, because the separation between means of the two redundant-dimension conditions is, by definition, zero. If the single-dimension conditions were not exactly equivalent, as they would hardly be for every subject, then less bias would be introduced into this condition because of the nonzero separation of means. Thus, the difference in potential bias should cause more underestimation of the redundant-condition mean than of the smaller of the two single-condition means. ${ }^{9}$

Finally, two generalizations of the bias studied here should be mentioned. First, bias in estimating the smallest condition mean will become more serious with increases in the number of conditions involved. We have considered here only the case of two conditions, and shown how sampling error causes the smaller of the sample means to underestimate the smaller of the true means. The underestimation will tend to be more extreme if one uses the smallest of more than two sample means to estimate the smallest of the corresponding condition means, because the additional samples will add more opportunities for sampling error. Second, analogous problems of bias arise when one wishes to establish the maximum of two or more true average RTs (e.g., Neisser, 1974). In this case, the maximum of the sample averages will tend to overestimate the true RT, because chance will favor the selection of spuriously large averages.

\section{Conclusions}

When trying to estimate the smaller of two true mean RTs for the purpose of testing race models, it is not a good strategy to simply use the smaller of two observed mean RTs, for each subject. A better estimation procedure is to first test for a significant difference between the two subject means (e.g., with a $t$ test), using a somewhat liberal criterion for rejecting the null hypothesis of no difference (e.g., $p<.10$ ). If the means are significantly different by the liberal criterion, the smaller of the two means is used as the estimate; if not, the average of the two means is used.

A more conservative procedure is to construct an interval estimate of the desired value. Estimators biased in different directions can provide reasonable upper and lower bounds for the true value. Averages of these bounds across subjects can then be used to define conservative bounds for the population average of the parameter in question.

\section{REFERENCECES}

Ashby, F. G., \& ToWNSEND, J. T. (1986). Varieties of perceptual independence. Psychological Review, 93, 154-179.

Biederman, I., Checkosky, S. (1970). Processing redundant information. Journal of Experimental Psychology, 83, 486-490.

Callaghan, T. C., Lasaga, M. I., \& Garner, W. R. (1986). Visual texture segregation based on orientation and hue. Perception \& Psychophysics, 39, 32-38.

CoLonius, H. (1986). Measuring channel dependence in separate activation models. Perception \& Psychophysics, 40, 251-255.

ErIKSEN, C. W. (1988). A source of error in attempts to distinguish coactivation from separate activation in the perception of redundant targets. Perception \& Psychophysics, 44, 191-193.

GARNER, W. R. (1969). Speed of discrimination with redundant stimulus attributes. Perception \& Psychophysics, 6, 221-224.

GARNER, W. R. (1983). Asymmetric interactions of stimulus dimensions in perceptual information processing. In T. J. Tighe \& B. E. Shepp (Eds.), Perception, cognition \& development: Interactional analyses (pp. 1-38). Hillsdale, NJ: Erlbaum.

HawkINs, H. L. (1969). Parallel processing in complex visual discrimination. Perception \& Psychophysics, 5, 56-64.

Hays, W. (1973). Statistics for the social sciences. New York: Holt, Rinehart \& Winston.

HoGg, R. V. (1974). Adaptive robust estimators: A partial review and some suggestions for future applications and theory. Jourmal of the American Statistical Association, 69, 909-923.

HuGHes, H. C. (1986). Asymmetric interference between components of suprathreshold compound gratings. Perception \& Psychophysics, 40, 241-250. 
LOGAN, G. D. (1985). On the ability to inhibit simple thoughts and actions: II. Stop-signal studies of repetition priming. Journal of Experimental Psychology: Leaming, Memory, \& Cognition, 11, 675-691.

McCormack, P., WRight, N. (1964). The positive skew observed in reaction time. Canadian Journal of Psychology, 18, 43-51.

Miller, J. O. (1978). Multidimensional same-different judgments: Evidence against independent comparisons of dimensions. Journal of $E x$ perimental Psychology: Human Perception \& Performance, 4, 411-422.

MILLER, J. O. (1981). Global precedence in attention and decision. Journal of Experimental Psychology: Human Perception \& Performance, 7, 1161-1174.

Miller, J. O. (1982). Divided attention: Evidence for coactivation with redundant signals. Cognitive Psychology, 14, 247-279.

NeIsser, U. (1974). Practiced card sorting for multiple targets. Memory \& Cognition, 2, 781-785.

Pomerantz, J. R., \& SAGER, L. C. (1975). Asymmetric integrality with dimensions of visual pattern. Perception \& Psychophysics, 18, $460-466$.

RAAB, D. H. (1962). Statistical facilitation of simple reaction times. Transactions of the New York Academy of Sciences, 24, 574-590.

SCHNEIDER, W., SHIFFrin, R. M. (1977). Controlled and automatic human information processing: I. Detection, search, and attention. Psychological Review, 84, 1-66.

ULRICH, R., \& GIRAY, M. (1986). Separate-activation models with variable base times: Testability and checking of cross-channel dependency. Perception \& Psychophysics, 39, 248-259.

Van der Heuden, A. H. C., La Heu, W., Boer, J. P. A. (1983). Parallel processing of redundant targets in simple visual search tasks. Psychological Research, 45, 235-254.

\section{NOTES}

1. This point was raised by Lester Krueger.

2. It would not be known, however, if the trial-by-trial race model was correct or if information from the two attributes was somehow integrated and used together.

3. Biederman and Checkosky (1970) actually used a slightly more complicated procedure. We will discuss the simplified procedure for now, both to simplify the exposition and because this is the procedure that most subsequent researchers have used. Biederman and Checkosky's actual procedure will be considered in the General Discussion section.

4. To simplify the exposition, the problem will be introduced in terms of the estimation of population means, although the arguments apply equally well to medians.

5. The single-dimension condition is the simplest unit of simulation, because parameter values are fixed. The average bias expected across a whole experiment is simply the average of the biases expected under the different combinations of parameter values occuring within that experiment (i.e., for different subjects and trial blocks).

6. In a subsequent set of simulations, we examined the behavior of all-or-none estimators with critical $p$ levels ranging from .05 to .10 in steps of .01 and from .11 to .25 in steps of .02 . These indicated that the optimal $p$ level is clearly in the range from .10 to .13 , and so the recommendation of .10 seems reasonable even after a more fine-grained examination of alternative $\boldsymbol{p}$ values.

7. Pooled standard deviations were computed as follows: The variance of an estimator was computed within each of the 180 conditions, and then these 180 variances were averaged across the conditions. The pooled standard deviation is the square root of the averaged variance. This pooling of variance is mathematically equivalent to the pooled error variance used in analysis of variance.

8. Since biases average across subjects, it is tempting to consider using an estimator that tends to overestimate the true value in some conditions and underestimate it by the same amount in others (e.g., Steinlike with $B=8.0$ ). If there were appropriate variation among subjects in parameter values, these biases might cancel out across the whole experiment so that the average estimate across subjects would be unbiased even though the estimate for any given subject was biased. We cannot really recommend this strategy, however, without quite a bit of prior information about the distributions of parameter values within the population. Without such information, it is impossible to know for sure that biases are likely to average out properly in any particular empirical setting.

9. In a slightly more elaborate design, Garner (1969) compared the fastest of three single-dimension conditions with the fastest of three redundant-dimension conditions. This procedure seems to suffer from the same potential problem as that of Biederman and Checkosky (1970).

\section{APPENDIX}

This Appendix describes the different estimators that we tested in our search for an estimator better than the standard one. The different estimators are described for the computations using sample means; for the computations using medians, the computations were identical except for the use of the different sample statistic.

All of the other estimators were based on a statistical comparison, using the $F$ test, of the null hypothesis that the RTs from the two conditions came from populations with equal means. The rationale behind this test is based on the idea that the smaller of the two observed means $(S)$ is more likely to be the correct estimate if there is good evidence that the true condition means are actually different. If there is little or no evidence that the true condition means are different, then the average of the two means $(A)$ is more likely to be the correct estimate. In the former case, we can be confident that the smaller sample mean actually came from the condition with the smaller true mean. In the latter case, however, there is a greater chance that the condition with the smaller true mean accidentally produced the larger sample mean, in which case we would be introducing bias by selecting the smaller sample mean as the estimator. Thus, the significance of the $F$ test comparing the two conditions is relevant to choosing whether to use the smaller or the average of the two observed means as the estimator.

One class of estimators, referred to as the all-or-none estimators, used either $S$ or $A$ as the estimate, depending on whether or not the two condition means were significantly different by the $F$ test. That is,

$$
\text { Estimate }=\left\{\begin{array}{l}
S \text { if } F \text { significant } \\
A \text { if } F \text { not significant. }
\end{array}\right.
$$

Four estimators in this class were examined. These estimators differed according to the critical significance level chosen for the $F$ test: $.01, .05, .10$, or .25 .

A probability-weighted average estimator was also constructed using the attained $p$ value $(\mathrm{Pa})$ of the $F$ test. This is a continuously varying version of the all-or-none class of estimators:

$$
\text { Estimate }=A \times P a+S \times(1-P a) .
$$

This estimator is a weighted average of the smaller of the two means and the average of the two means. The weight on the smaller mean is large to the extent that the means are significantly different, and the weight on the average is large to the extent that the means are not significantly different. This weighting scheme is suggested by the earlier argument that the smaller mean should be weighted more heavily to the extent that we can be sure that it came from the condition with the smaller true mean.

Ten estimators were selected to investigate a class of "Steinlike" estimators described by Hogg (1974). These estimates are based on the somewhat counterintuitive fact that if one wishes to estimate the means for a set of normally distributed popula- 
tions in the presence of a null hypothesis that the population means are all equal, it is not best to simply use the set of sample means as the estimate. It is better to estimate each population mean with the weighted average of its sample mean and the mean of the other samples, where the weights are a function of the $F$ value obtained in testing the null hypothesis. This result, translated to the present case, suggests estimators of the following form:

$$
\text { Estimate }=A \times \frac{B}{F+B}+S \times \frac{F}{F+B},
$$

where $F$ is the obtained value of the $F$ test and $B$ is an arbitrary constant. The 10 estimators in this class differed in the value of $B$ used. Values of $B$ ranged from 0.5 to 4.0 in steps of 0.5 , with additional values of 8 and 12 . These values were chosen to adjust the weighting fractions over an appropriate range, given the values of $F$ expected.

(Manuscript received August 10, 1987; revision accepted for publication June 6,1988 .) 